\title{
Association between air pollution and coronary artery calcification within six metropolitan areas in the USA (the Multi- Ethnic Study of Atherosclerosis and Air Pollution): a longitudinal cohort study
}

\begin{abstract}
Joel D Kaufman, Sara D Adar, R Graham Barr, Matthew Budoff, Gregory L Burke, Cynthia L Curl, Martha L Daviglus, Ana V Diez Roux, Amanda J Gassett, David R Jacobs Jr, Richard Kronmal, Timothy V Larson, Ana Navas-Acien, Casey Olives, Paul D Sampson, Lianne Sheppard, David S Siscovick, James H Stein, Adam A Szpiro, and Karol E Watson Department of Environmental and Occupational Health Sciences (Prof J D Kaufman MD, A J Gassett MS, C Olives PhD, Prof L Sheppard PhD), Department of Epidemiology (Prof J D Kaufman), Department of Medicine (Prof J D Kaufman, Prof Emeritus D S Siscovick MD), Department of Biostatistics (Prof R Kronmal PhD, Prof L Sheppard PhD, A A Szpiro PhD), Department of Civil and Environmental Engineering (Prof T V Larson PhD), and Department of Statistics (Prof P D Sampson), University of Washington, Seattle, WA, USA; Department of Epidemiology, University of Michigan, Ann Arbor, MI, USA (S D Adar ScD); Department of Medicine and Department of Epidemiology, Columbia University, New York, NY, USA (R G Barr MD); Los Angeles Biomedical Research Institute at Harbor, UCLA Medical Center, Torrance, CA, USA (Prof M Budoff MD); Division of Public Health Sciences, Wake Forest University, WinstonSalem, NC, USA (Prof G L Burke MD); Department of Community and Environmental Health, Boise State University, Boise, ID, USA (C L Curl PhD); Feinberg School of Medicine, Northwestern University, Evanston, IL, USA (Prof M L Daviglus MD); Institute for Minority Health Research, University of Illinois at Chicago, Chicago, IL, USA (Prof M L Daviglus); School of Public Health, Drexel University, Philadelphia, PA, USA (Prof A V Diez Roux MD); School of Public Health, Division of Epidemiology and Community Health, University of Minnesota, Minneapolis, MN, USA (Prof D R Jacobs PhD); Department of Environmental Health Sciences, Johns Hopkins University, Baltimore, MD, USA (A Navas-Acien MD); New York Academy of Medicine, New York, NY, USA (Prof D S Siscovick Emeritus); Department of Medicine, University of Wisconsin School of Medicine and Public Health, Madison, WI, USA (Prof J H Stein MD); and Department of Medicine, Division of Cardiology, University of California Los Angeles, Los Angeles, CA, USA (Prof K E Watson MD)
\end{abstract}

\section{Summary}

\footnotetext{
Correspondence to: Prof Joel D Kaufman, University of Washington, Seattle, WA 98105, USA joelk@u.washington.edu. Contributors

All authors contributed substantially to the conception or design of the manuscript or the acquisition, analysis, or interpretation of data for the manuscript. All authors contributed to critical revision of the manuscript for important intellectual content. All authors approved the final version submitted. JDK directed the MESA Air investigator team and the remaining investigators are listed alphabetically.

Declaration of interests

We declare no competing interests.
} 
Background-Long-term exposure to fine particulate matter less than $2.5 \mu \mathrm{m}$ in diameter $\left(\mathrm{PM}_{2.5}\right)$ and traffic-related air pollutant concentrations are associated with cardiovascular risk. The disease process underlying these associations remains uncertain. We aim to assess association between long-term exposure to ambient air pollution and progression of coronary artery calcium and common carotid artery intima-media thickness.

Methods-In this prospective 10-year cohort study, we repeatedly measured coronary artery calcium by CT in 6795 participants aged 45-84 years enrolled in the Multi-Ethnic Study of Atherosclerosis and Air Pollution (MESA Air) in six metropolitan areas in the USA. Repeated scans were done for nearly all participants between 2002 and 2005, for a subset of participants between 2005 and 2007, and for half of all participants between 2010 and 2012. Common carotid artery intima-media thickness was measured by ultrasound in all participants at baseline and in 2010-12 for 3459 participants. Residence-specific spatio-temporal pollution concentration models, incorporating community-specific measurements, agency monitoring data, and geographical predictors, estimated concentrations of $\mathrm{PM}_{2.5}$ and nitrogen oxides $\left(\mathrm{NO}_{\mathrm{X}}\right)$ between 1999 and 2012. The primary aim was to examine the association between both progression of coronary artery calcium and mean carotid artery intima-media thickness and long-term exposure to ambient air pollutant concentrations $\left(\mathrm{PM}_{2.5}, \mathrm{NO}_{\mathrm{X}}\right.$, and black carbon) between examinations and within the six metropolitan areas, adjusting for baseline age, sex, ethnicity, socioeconomic characteristics, cardiovascular risk factors, site, and CT scanner technology.

Findings-In this population, coronary calcium increased on average by 24 Agatston units per year (SD 58), and intima-media thickness by $12 \mu \mathrm{m}$ per year (10), before adjusting for risk factors or air pollutant exposures. Participant-specific pollutant concentrations averaged over the years 2000-10 ranged from 9.2-22.6 $\mu \mathrm{g} \mathrm{PM}_{2.5} / \mathrm{m}^{3}$ and 7.2-139.2 parts per billion (ppb) $\mathrm{NO}_{\mathrm{X}}$. For each $5 \mu \mathrm{g} \mathrm{PM} 2.5 / \mathrm{m}^{3}$ increase, coronary calcium progressed by 4.1 Agatston units per year (95\% CI 1.4 6.8) and for each $40 \mathrm{ppb} \mathrm{NO}_{\mathrm{X}}$ coronary calcium progressed by 4.8 Agatston units per year (0.98.7). Pollutant exposures were not associated with intima-media thickness change. The estimate for the effect of a $5 \mu \mathrm{g} / \mathrm{m}^{3}$ higher long-term exposure to $\mathrm{PM}_{2.5}$ in intima-media thickness was -0.9 $\mu \mathrm{m}$ per year $(95 \% \mathrm{CI}-3.0$ to $1 \cdot 3)$. For $40 \mathrm{ppb}$ higher $\mathrm{NO}_{\mathrm{X}}$, the estimate was $0.2 \mu \mathrm{m}$ per year $(-1.9$ to $2 \cdot 4)$.

Interpretation-Increased concentrations of $\mathrm{PM}_{2.5}$ and traffc-related air pollution within metropolitan areas, in ranges commonly encountered worldwide, are associated with progression in coronary calcification, consistent with acceleration of atherosclerosis. This study supports the case for global efforts of pollution reduction in prevention of cardiovascular diseases.

Funding-US Environmental Protection Agency and US National Institutes of Health.

\section{Introduction}

Particulate air pollution and traffic-related air pollutants are associated with overall mortality, cardiovascular mortality, and cardiovascular disease events. In particular, longterm exposure to high concentrations of air pollutants has been associated with risk of myocardial infarction and stroke. ${ }^{1}$ However, previous studies of cardiovascular disease and air pollution have had short follow-up duration, have often been limited by between-city exposure contrasts without precisely accounting for within-city variation, and have comprised secondary analyses of existing datasets collected to test other hypotheses. 
Furthermore, the underlying pathological process has not been well established, leaving the biological plausibility of these findings open to question.

To reduce uncertainties in the understanding of the potential health effects of ambient air pollutants, the US Environmental Protection Agency (EPA) supported an unprecedented effort to characterise pollutant exposures in participants of the National Heart, Lung, and Blood Institute's Multi-Ethnic Study of Atherosclerosis (MESA). ${ }^{2}$ The resultant study (the Multi-Ethnic Study of Atherosclerosis and Air Pollution, [MESA Air] $)^{3}$ tested a priori the associations of air pollution concentrations, specifically particulate matter of less than 2.5 $\mu \mathrm{m}$ in diameter $\left(\mathrm{PM}_{2.5}\right)$, nitrogen oxides $\left(\mathrm{NO}_{\mathrm{X}}\right)$, and black carbon, with progression of subclinical arteriosclerosis. We report the association between long-term exposure to ambient air pollution and progression of coronary artery calcium and common carotid artery intima-media thickness.

\section{Methods}

\section{Study design and participants}

The designs of the MESA ${ }^{2}$ and MESA Air ${ }^{3}$ studies have been described previously. Briefly, MESA recruited a cohort of 6814 participants with no history of clinical cardiovascular disease from four ethnic groups (Hispanic, black, white, and Chinese), with sex balance and uniform age distribution (range 45-84 years at recruitment) in six areas of the USA: Baltimore, MD; Chicago, IL; Los Angeles County, CA; New York City, NY; St Paul, MN; and Winston-Salem, NC. Community-based strategies that varied by clinical centre were used to recruit participants. Recruitment and baseline examinations were done between July 17, 2000, and Aug 29, 2002. Between Feb 22, 2005, and May 9, 2007, MESA Air recruited 257 additional participants in Rockland County, NY (grouped as being from the same area as New York City, NY participants); Riverside County, CA (grouped as being from the same area as Los Angeles County, CA participants); and a coastal area of Los Angeles County, $\mathrm{CA}$, to add heterogeneity in air pollution exposures. The study protocol was approved by the institutional review board at each of the six study centres, and participants provided written informed consent upon their arrival at the study clinic.

\section{Procedures}

All participants received CT scans at baseline to measure coronary artery calcium as previously described. ${ }^{4}$ Repeated scans were done for nearly all participants between 2002 and 2005, for a subset of participants between 2005 and 2007, and for half of all participants between 2010 and 2012. CT technology differed between clinical centres and over time. ${ }^{5} \mathrm{~A}$ four-density calibration phantom was imaged with each scan to enhance comparability of images between scanners and to scale the voxels in each composite scan before the calculation of coronary artery calcium scores. Scans were scored in the Harbor-UCLA Los Angeles Biomedical Research Institute by the Agatston method. ${ }^{4}$

To measure the common carotid artery intima-media thickness, one ultrasound and transducer model (Logiq 700, M12L, GE Medical Systems, Waukesha, WI, USA) were used at all sites in all examinations. ${ }^{6}$ Images were read by the University of Wisconsin Carotid 
Ultrasound Reading Center. Baseline images were read only for participants with images from the 2010-12 examination. ${ }^{6}$

\section{Exposure assessment}

The MESA Air pollution measurement and modelling methods have been described previously. ${ }^{3,7,8}$ MESA Air measured ambient $\mathrm{PM}_{2.5}, \mathrm{NO}_{\mathrm{X}}$, nitrogen dioxide $\left(\mathrm{NO}_{2}\right)$, and black carbon (assessed by light absorption) at 27 long-term sites, 771 community snapshot locations (simultaneous 2-week measurements collected on three occasions), and outside 697 participants' homes between 2005 and 2009 to sup ple ment measurements from Environmental Protection Agency Air Quality System monitoring locations.

Participants reported all residential addresses from 1980 to 2012. Community-specific spatio-temporal models were developed to predict pollutant concentrations at participants' residences for each fortnight from 1999 to 2012, with statistical methods to accommodate irregular monitoring data and incorporate all monitoring results. These models explained $90-97 \%$ of the variation (model-fit $\mathrm{R}^{2}$ ) in measurements at participant homes. The crossvalidated $R^{2}$ values (assessing out-of-sample validation) for predictions from the areaspecific models at residence locations varied by site. Median (range) $\mathrm{R}^{2}$ values for these models were $0.79(0.54-0.85)$ for $\mathrm{PM}_{2.5}, 0.78(0.45-0.90)$ for $\mathrm{NO}_{2}, 0.72(0.50-0.92)$ for $\mathrm{NO}_{\mathrm{X}}$, and $0.67(0.51-0.78)$ for black carbon. These $\mathrm{R}^{2}$ values at participants' homes leverage temporal as well as spatial variability. $\mathrm{R}^{2}$ values from the cross-validation of the measured long-term fixed sites were similar. ${ }^{8}$

MESA Air participants completed detailed questionnaires at recruitment and after life changes, including moving homes. Examples of items queried included heating choices, air conditioner use, and window opening, and time spent indoors and outdoors, during summer and winter. ${ }^{9}$ Responses, meteorology, and an outdoor $\mathrm{PM}_{2.5}$ tracer (particulate sulphur assessed in concurrent samples inside and outside selected homes) were used to predict the fraction of ambient $\mathrm{PM}_{2.5}$ infiltrating homes. ${ }^{10}$ Indoor $\mathrm{PM}_{2.5}$ exposures were calculated as the predicted fortnight's outdoor $\mathrm{PM}_{2.5}$ concentration multiplied by the weather-specific and residence-specific infiltration fraction. An individually-weighted exposure to ambientderived $\mathrm{PM}_{2.5}\left(\mathrm{PM}_{2.5 \text { iwa }}\right)$ for each fortnight was calculated by time-weighting the outdoor concentration by time spent outdoors, and indoor exposure by time spent indoors.

Long-term exposures were the average of fortnightly residence-specific predictions from recruitment to follow-up for each examination. Year 2000 concentrations at the baseline address were used to model baseline cross-sectional relationships. Outdoor concentrations of black carbon were generated only for the years 2006-08 because comparable air quality system data were not available at other times (EPA's measurement method for black carbon was not comparable to the study-specific measurement method). Long-term black carbon averages were calculated by weighting the residence-specific 2006-08 means by the amount of time participants lived at each location between their examinations. 


\section{Statistical analysis}

The study was designed to be adequately powered to detect air pollutant effects of 2 Agatston units per year or $7 \mu \mathrm{m}$ per year intima-media thickness per $10 \mu \mathrm{g} \mathrm{per} \mathrm{m}^{3} \mathrm{PM}_{2.5}$, based on pollution contrasts observed between MESA communities before 2003.

The associations of progression of coronary artery calcium and mean intima-media thickness with long-term average outdoor pollutant concentrations $\left(\mathrm{PM}_{2.5}, \mathrm{NO}_{\mathrm{X}}\right.$, and black carbon) were the primary interests, with $\mathrm{NO}_{2}$ and ambient-derived $\mathrm{PM}_{2.5}$ assessed as secondary. The primary adjustment model included baseline age, sex, ethnicity, site, CT scanner type (in the coronary artery calcium analysis), body-mass index (BMI), physical activity, smoking and second-hand smoke exposure (both time-varying), employment outside the home, total cholesterol, high density lipoprotein (HDL), triglycerides, statin use (time-varying), neighbourhood socioeconomic index, level of education, income, and the interactions between these variables and study time. Participants were censored at the time of coronary revascularisation procedures for analysis of coronary artery calcium. Additional models incorporated information on blood pressure and diabetes.

A mixed model jointly analysed both the cross-sectional association between air pollution and the outcomes at baseline examination and the relationship between air pollution and the rate of progression. ${ }^{11}$ Repeated measurements were modelled as a function of study time, with time-varying exposures modelled as an interaction with time to obtain a rate.

Participant-specific random intercepts and slopes were included, along with random intercepts for neighbourhood clusters. We investigated potential effect modification by sex, ethnicity, obesity (BMI $<30 \mathrm{~kg} / \mathrm{m}^{2}$ vs BMI $330 \mathrm{~kg} / \mathrm{m}^{2}$ ), age category (10-year intervals), smoking status, hypertensive status, diabetes status, HDL cholesterol concentration (HDL cholesterol $<1.03 \mathrm{mmol} / \mathrm{L}$ vs HDL cholesterol $\geq 1.04 \mathrm{mmol} / \mathrm{L}$ ), total cholesterol (total $<5 \cdot 17$ $\mathrm{mmol} / \mathrm{L}$, total $5 \cdot 17-6 \cdot 21 \mathrm{mmol} / \mathrm{L}$, or total $>6 \cdot 21 \mathrm{mmol} / \mathrm{L}$ ), and LDL cholesterol concentration (LDL cholesterol <2.59 mmol/L, LDL cholesterol 2.59-3.36 mmol/L, LDL cholesterol 3.36-4.14 $\mathrm{mmol} / \mathrm{L}$, or LDL cholesterol $>4.14 \mathrm{mmol} / \mathrm{L}$ ). Evidence for effect modi fication was assessed by including three-way inter action terms between study time, the effect modifier, and air pollution concentration. A concentration-response curve was generated using a thin plate regression spline with five degrees of freedom for long-term average $\mathrm{PM}_{2.5}$ concentrations.

We also examined the relationship between pollutants and relative progression of coronary artery calcium, using a $\ln$ (Agatston score plus 25 ) transformation of the outcome.

\section{Role of the funding source}

This study was overseen by a Steering Committee and an External Scientific Advisory Committee (ESAC). The primary funder of MESA Air, the US Environmental Protection Agency, had ex-officio representation on the ESAC. The funder had no role in data collection, analysis, interpretation, or writing of the study reports. All authors were provided complete access to the data and all authors share responsibility for the decision to submit the manuscript. 


\section{Results}

Of the 7060 participants initially enrolled, 5834 underwent at least two examinations and had suffcient data to be included longitudinally in the analysis of coronary artery calcium. 961 participants were included only at baseline. The mean age of the cohort at baseline was 62 years (SD 10), and 3593 (53\%) of the 6795 participants assessed were women. Overall, the cohort included 2678 (39\%) white, 795 (12\%) Chinese, 1824 (27\%) black, and 1498 (22\%) Hispanic participants (table). The differences in population characteristics between sites, notably in ethnicity and level of education, reflect purposefully implemented sampling strategies; differences in smoking rates reflect community differences. Mean follow-up time for participants with at least two coronary artery calcium measurements was 6.2 years (SD $3.5)$ and for those with intima-media thickness measurements from at least two timepoints was $9 \cdot 2$ years $(1 \cdot 8)$.

Figure 1 shows summary statistics of air pollutant concentrations in the year 2000 and over follow-up. Long-term average levels of pollution were lower than levels of pollution in 2000. Mean concentrations also varied between sites by pollutant, with $\mathrm{PM}_{2.5}$ concentrations being highest in Los Angeles County and lowest in St Paul, and $\mathrm{NO}_{\mathrm{X}}$ and $\mathrm{NO}_{2}$ being highest in New York City and lowest in Winston-Salem (figure 1). Figure 2 shows between-city and within-city exposure contrasts of concentrations of $\mathrm{PM}_{2.5}$ and $\mathrm{NO}_{\mathrm{X}}$ in 2005 (appendix p 11).

The mean progression rate over follow-up for coronary artery calcium was 24 Agatston units per year (SD 58) and for intima-media thickness was $12 \mu \mathrm{m}$ per year (10); at baseline, coronary artery calcium scores were 145 Agatston units (407). Because the intima-media thickness analysis was restricted to participants who returned for ultrasound scans during the last examination, participants with intima-media thickness data were on average 2 years younger, more educated, and less likely to have diabetes than were those included in the coronary artery calcium analysis (appendix p 15).

In the primary analysis adjusted for potential confounders, a $5 \mu \mathrm{g} / \mathrm{m}^{3}$ higher $\mathrm{PM}_{2.5}$ concentration was associated with 4.1 Agatston units per year (95\% CI 1.4-6.8) increased rate of coronary artery calcium progression (figure 3 ). A 40 parts per billion (ppb) higher $\mathrm{NO}_{\mathrm{X}}$ concentration was associated with a 4.8 Agatston units per year $(0 \cdot 9-8 \cdot 7)$ increased rate of coronary artery calcium progression, and a $10 \mathrm{ppb}$ higher $\mathrm{NO}_{2}$ concentration was associated with 2.7 Agatston units per year ( -0.3 to 5.7$)$ increased rate of coronary artery calcium progression. Neither black carbon nor ambient-derived $\mathrm{PM}_{2.5}$ were associated with coronary artery calcium progression $\left(0.1\right.$ Agatston units per year for a $0.5 \mu \mathrm{g} / \mathrm{m}^{3}$ higher black carbon concentration [-3.8 to 4.1$]$ and 1.0 Agatston units per year for a $5 \mu \mathrm{g} / \mathrm{m}^{3}$ higher ambient-derived $\mathrm{PM}_{2.5}$ exposure [ -1.9 to 3.9$]$ ). Results were similar in models incorporating blood pressure and diabetes status.

Pollutant exposures were not associated with intima-media thickness change. The estimate for the effect of a $5 \mu \mathrm{g} / \mathrm{m}^{3}$ higher long-term exposure to $\mathrm{PM}_{2.5}$ in intima-media thickness was $-0.9 \mu \mathrm{m}$ per year $(95 \% \mathrm{CI}-3.0$ to $1 \cdot 3)$. For $40 \mathrm{ppb}$ higher $\mathrm{NO}_{\mathrm{X}}$, the estimate was 0.2 $\mu \mathrm{m}$ per year (-1.9 to 2.4$)$. 
Results for both outcomes were consistent in sensitivity analyses. The associations of $\mathrm{PM}_{2 \cdot 5}$ and $\mathrm{NO}_{\mathrm{X}}$ with coronary artery calcium progression were attenuated with widened confidence intervals if one was adjusted for the other. Exposure to outdoor $\mathrm{PM}_{2.5}, \mathrm{NO}_{\mathrm{X}}$, $\mathrm{NO}_{2}$, and ambient-derived $\mathrm{PM}_{2.5}$ were all positively associated with relative coronary artery calcium progression (appendix p 13).

The concentration-response function between outdoor $\mathrm{PM}_{2.5}$ and coronary artery calcium progression concentration suggests attenuation of the association at higher concentrations (figure 3). Evidence for effect modification by several factors was weak and inconsistent between $\mathrm{PM}_{2.5}$ and $\mathrm{NO}_{\mathrm{X}}$, although it suggested that the effects of exposures to these pollutants might be greater in older, non-obese, and hypertensive individuals (figure 4).

\section{Discussion}

In this multi-ethnic prospectively studied population, ambient concentrations of $\mathrm{PM}_{2.5}$ and $\mathrm{NO}_{\mathrm{X}}$ were strongly associated with accelerated atherosclerosis, as shown by assessment of coronary artery calcium over a 10 -year period. Air pollution was not associated with progression of intima-media thickness. This study benefited from state-of-the-art exposure estimation at the time and location of each residence during follow-up and incorporated high-quality information about potential confounding factors, including time-varying covariates such as statin use. The cohort-focused air quality monitoring effort and spatiotemporal modelling methods enabled us to generate individually resolved exposures and examine relationships between atherosclerosis progression and air pollution over time, using within-city contrasts with an unprecedented level of accuracy. These results provide important evidence that long-term exposure to these ambient air pollutants is associated with atherosclerosis progression in the coronary arteries and can explain previous findings that pollutants are associated with cardiovascular events and mortality.

Exposures during follow-up of this cohort were low by historical and international standards. The present US National Ambient Air Quality Standards ${ }^{12}$ permit annual average $\mathrm{PM}_{2.5}$ concentrations of $12 \mu \mathrm{g} / \mathrm{m}^{3}$ and the European Union Air Quality Standards ${ }^{13}$ permit 25 $\mu \mathrm{g} / \mathrm{m}^{3}$, whereas the mean ambient $\mathrm{PM}_{2.5}$ concentration that participants in our study were exposed to over $2000-10$ was $14 \cdot 2 \mu \mathrm{g} / \mathrm{m}^{3}$ (range 9.2-22.6). The concentrations in rapidly industrialising countries are substantially higher. ${ }^{14}$

Calcified plaques in the coronary arteries have been consistently associated with cardiovascular disease in both clinical trials and observational research. ${ }^{15}$ Coronary artery calcium is a very strong risk marker of future ischaemic vascular events. Although most often studied as a one-time measure of atherosclerotic extent and plaque burden, ${ }^{16}$ change in coronary artery calcium also predicts subsequent ischaemic events. ${ }^{2}$ Risk factors that accelerate coronary artery calcium progression (including age, male sex, adiposity, systolic blood pressure, smoking, and diabetes) are also strong predictors of subsequent ischaemic events. ${ }^{17}$ Coronary artery calcium meas urements might represent more mature atherosclerotic lesions than forming or vulnerable plaques. ${ }^{18}$ 
The association between coronary artery calcium progression and air pollution has not been reported, although the plausibility of a causal relationship between air pollution and atherosclerosis is suggested through several mechanisms. ${ }^{19}$ In a cross-sectional analysis in the the Heinz-Nixdorf Recall study, ${ }^{20}$ coronary artery calcium was higher in individuals living near roads than in those who did not live near major roads. Our findings provide evidence that exposure to air pollution is associated with coronary artery calcium progression.

Although coronary artery calcium progression was associated with $\mathrm{PM}_{2.5}$ and $\mathrm{NO}_{\mathrm{X}}$, it was not associated with black carbon. Unlike the other pollutants, for which exposures were estimated between 1999 and 2012, black carbon exposures were limited to only spatial contrasts in 2006-08; hence, analyses could not capture the decreasing trends in pollutant concentrations recorded during follow-up. ${ }^{21}$ Additionally, coronary artery calcium progression was not as strongly associated with $\mathrm{NO}_{2}$ as it was with total $\mathrm{NO}_{\mathrm{X}}$. The total $\mathrm{NO}_{\mathrm{X}}$ is highest in the most near-road environments (measured in previous research as proximity to a major roadway or time in traff c), ${ }^{22}$ and might better represent the group of primarily emitted traff c-related air pollutants present in these locations. Therefore, characterisation of $\mathrm{NO}_{\mathrm{X}}$ exposure might be a better way to capture the effects of the nearroad environment on health.

We noted a somewhat stronger association between $\mathrm{PM}_{2.5}$ and coronary artery calcium progression in hypertensive, in non-obese, and in individuals older than 65 years. The findings with age and hypertension suggest a synergistic association between air pollutants and these two strong risk factors for progression of atherosclerosis, though this association was not found for other strong risk factors such as diabetes or elevated cholesterol levels. The finding that pollutant associations with coronary artery calcium progression appeared stronger in non-obese participants is not what would be expected because inflammatory and metabolic consequences of obesity are thought to share mechanistic pathways with those of air pollutants. ${ }^{19}$ Although this study's sample size and precision provided adequate statistical power for the primary comparisons, analyses of effect modification were less well powered.

Our findings for the effect of pollutants on coronary artery calcium progression were robust to a variety of sensitivity analyses and did not differ depending on stages of control of potential confounding variables. This result strengthens our confidence in these associations. In addition, air pollutant relationships were recorded whether the outcome was measured as an absolute or relative change in calcification. Although absolute change in the extent of calcifications was our a-priori outcome choice, assessment of the outcome as a relative change did suggest additional associations with $\mathrm{NO}_{2}$ and ambient-derived $\mathrm{PM}_{2.5}$ that were not observed with the absolute change outcome.

An association between air pollution and progression of carotid wall thickness has been noted in some, but not all, previous studies. ${ }^{23,24}$ An interim analysis ${ }^{25}$ in MESA showed that exposure to a $2.5 \mu \mathrm{g} / \mathrm{m}^{3}$ higher $\mathrm{PM}_{2.5}$ concentration was associated with a $5 \mu \mathrm{m}$ per year increase in intima-media thickness progression; the interim study used a different approach to image analysis, a less-developed approach to exposure estimation, and a much shorter period of follow-up. An observational study ${ }^{26}$ within clinical trial data showed associations 
between $\mathrm{PM}_{2.5}$ and intima-media thickness progression in some subgroups. Carotid wall thickness is a challenging outcome for observational studies because the change in intimamedia thickness over time is small relative to the measurement error at each timepoint. The mechanism by which air pollution might accelerate atherosclerosis might also be unrelated to intima-media thickness, which is a marker of arterial injury rather than atherosclerosis per se. ${ }^{27}$ Unlike coronary artery calcium, change over time in intima-media thickness is not predictive of subsequent cardiovascular disease events in observational studies, although it is a commonly used outcome in pharmaceutical studies. ${ }^{28,29}$ In MESA participants, coronary artery calcium has been a much stronger predictor of subsequent coronary heart disease events than intima-media thickness. ${ }^{30}$

The MESA cohort provides an extraordinarily well characterised population in terms of potential confounders of the relationship between air pollution and cardiovascular disease. Nevertheless, residual confounding by unmeasured factors remains a possibility.

Additionally, though we chose a-priori exposures and outcomes of interest, the presence of more than one exposure and outcome in our analyses could be criticised for including multiple comparisons.

This study focused on the health effects of ambient-derived air pollutants on cardiovascular health. Our primary exposure metrics focused on concentrations of pollutants outside homes, although individuals spend time in specific micro-environments, including indoors. We developed the ambient-derived $\mathrm{PM}_{2.5}$ measure specifically to address this issue, to better characterise actual exposure to ambient $\mathrm{PM}_{2.5}$ by adjusting outdoor concentrations by time spent indoors and infiltration of particles into the home. Because these predictions represent the product of two different modifiers of outdoor concentration (each imperfectly assessed and not available for all study participants) we believe that the additional error in exposure estimation was the primary driver for the weak associations reported for ambient-derived $\mathrm{PM}_{2.5}$. Full characterisation of time-location patterns and indoor exposures is notoriously diff cult. Ascertainment of highly resolved, individualised micro-environmental exposure estimates over several years of follow-up is elusive, hence our primary exposure estimation approach relies on outdoor concentrations.

In conclusion, evidence from this study provides strong biological support for the observation that long-term exposures to outdoor particulate matter and traff c-related air pollution, specifically $\mathrm{PM}_{2.5}$ and $\mathrm{NO}_{\mathrm{X}}$, are related to the development of atherosclerotic cardiovascular disease.

\section{Supplementary Material}

Refer to Web version on PubMed Central for supplementary material.

\section{Acknowledgments}

This research has been supported by a grant from the US Environmental Protection Agency's (EPA's) Science to Achieve Results (STAR) programme. This publication was developed under Assistance Agreement number RD831697 awarded by the EPA to the University of Washington (WA, USA). It has not been formally reviewed by EPA. The views expressed in this document are solely those of the authors and do not necessarily reflect those of the Agency. EPA does not endorse any products or commercial services mentioned in this publication. MESA and 
work in this manuscript was supported by the National Heart, Lung, and Blood Institute (NHLBI) through the following grants and contracts: N01-HC-95159, N01-HC-95160, N01-HC-95161, N01-HC-95162, N01-HC-95163, N01-HC-95164, N01-HC-95165, N01-HC-95166, N01-HC-95167, N01-HC-95168, N01-HC-95169; by the National Center for Research Resources through UL1-TR-000040 and UL1-TR-001079; and by the National Institute of Environmental Health Sciences through P50ES015915, P30ES07033, and K24ES013195. We thank the MESA Air participants as well as the staffand investigators of the MESA study for their valuable contributions. We also thank the members of our External Scientific Advisory Committee (appendix) for their dedication and contributions to our work.

\section{References}

1. Hoek G, Krishnan RM, Beelen R, et al. Long-term air pollution exposure and cardio- respiratory mortality: a review. Environ Health. 2013; 12:43. [PubMed: 23714370]

2. Bild DE, Bluemke DA, Burke GL, et al. Multi-Ethnic Study of Atherosclerosis: objectives and design. Am J Epidemiol. 2002; 156:871-81. [PubMed: 12397006]

3. Kaufman JD, Adar SD, Allen RW, et al. Prospective study of particulate air pollution exposures, subclinical atherosclerosis, and clinical cardiovascular disease: The Multi-Ethnic Study of Atherosclerosis and Air Pollution (MESA Air). Am J Epidemiol. 2012; 176:825-37. [PubMed: 23043127]

4. Carr JJ, Nelson JC, Wong ND, et al. Calcified coronary artery plaque measurement with cardiac CT in population-based studies: standardized protocol of Multi-Ethnic Study of Atherosclerosis (MESA) and Coronary Artery Risk Development in Young Adults (CARDIA) study. Radiology. 2005; 234:35-43. [PubMed: 15618373]

5. Budoff MJ, McClelland RL, Chung H, et al. Reproducibility of coronary artery calcified plaque with cardiac 64-MDCT: the Multi-Ethnic Study of Atherosclerosis. AJR Am J Roentgenol. 2009; 192:613-07. [PubMed: 19234254]

6. Tattersall MC, Gassett A, Korcarz CE, et al. Predictors of carotid thickness and plaque progression during a decade: the Multi-Ethnic Study of Atherosclerosis. Stroke. 2014; 45:3257-62. [PubMed: 25213342]

7. Cohen M, Adar S, Allen R, et al. Approach to estimating participant pollutant exposures in the Multi-Ethnic Study of Atherosclerosis and Air Pollution (MESA Air). Environ Sci Technol. 2009; 43:4687-93. [PubMed: 19673252]

8. Keller JP, Olives C, Kim SY, et al. A unified spatiotemporal modeling approach for predicting concentrations of multiple air pollutants in the Multi-Ethnic Study of Atherosclerosis and Air Pollution. Environ Health Perspect. 2015; 123:301-09. [PubMed: 25398188]

9. Spalt EW, Curl CL, Allen RW, et al. Time-location patterns of a diverse population of older adults: The Multi-Ethnic Study of Atherosclerosis and Air Pollution (MESA Air). J Expo Sci Environ Epidemiol. 2015 published online April 29. DOI:10.1038/jes.2015.29.

10. Allen RW, Adar SD, Avol E, et al. Modeling the residential infiltration of outdoor $\operatorname{PM}(2 \cdot 5)$ in the Multi-Ethnic Study of Atherosclerosis and Air Pollution (MESA Air). Environ Health Perspect. 2012; 120:824-30. [PubMed: 22534026]

11. Gassett AJ, Sheppard L, McClelland RL, et al. Risk factors for long-term coronary artery calcium progression in the Multi-Ethnic Study of Atherosclerosis. J Am Heart Assoc. 2015; 4:e001726. [PubMed: 26251281]

12. United States Environmental Protection Agency. National ambient air quality standards for particulate matter. Fed Regist. 2013; 78:3086-286.

13. [April 30, 2015] Directive 2008/50/EC of the European Parliament and of the Council of 21 May 2008 on ambient air quality and cleaner air for Europe. http://eur-lex.europa.eu/legalcontent/EN/TXT/HTML/?uri=CELEX:32008L0050\&from=EN

14. Brauer M, Amann M, Burnett RT, et al. Exposure assessment for estimation of the global burden of disease attributable to outdoor air pollution. Environ Sci Technol. 2012; 46:652-60. [PubMed: 22148428]

15. McEvoy JW, Blaha MJ, Defilippis AP, et al. Coronary artery calcium progression: an important clinical measurement? A review of published reports. J Am Coll Cardiol. 2010; 56:1613-22. [PubMed: 21050970] 
16. Sangiorgi G, Rumberger JA, Severson A, et al. Arterial calcification and not lumen stenosis is highly correlated with atherosclerotic plaque burden in humans: a histologic study of 723 coronary artery segments using nondecalcifying methodology. J Am Coll Cardiol. 1998; 31:126-33. [PubMed: 9426030]

17. Kronmal RA, McClelland RL, Detrano R, et al. Risk factors for the progression of coronary artery calcification in asymptomatic subjects-results from the Multi-Ethnic Study of Atherosclerosis (MESA). Circulation. 2007; 115:2722-30. [PubMed: 17502571]

18. Shaw LJ, Narula J, Chandrashekhar Y. The never-ending story on coronary calcium: is it predictive, punitive, or protective? J Am Coll Cardiol. 2015; 65:1283-85. [PubMed: 25835439]

19. Cosselman KE, Navas-Acien A, Kaufman JD. Environmental factors in cardiovascular disease. Nat Rev Cardiol. 2015; 12:627-42. [PubMed: 26461967]

20. Hoffmann B, Moebus S, Möhlenkamp S, et al. Residential exposure to traffic is associated with coronary atherosclerosis. Circulation. 2007; 116:489-96. [PubMed: 17638927]

21. Murphy D, Chow J, Leibensperger E, et al. Decreases in elemental carbon and fine particle mass in the United States. Atmos Chem Phys. 2011; 11:4679-86.

22. Karner AA, Eisinger DS, Niemeier DA. Near-roadway air quality: synthesizing the findings from real-world data. Environ Sci Technol. 2010; 44:5334-44. [PubMed: 20560612]

23. Lenters V, Uiterwaal C, Beelen R, et al. Long-term exposure to air pollution and vascular damage in young adults. Epidemiology. 2010; 21:512-20. [PubMed: 20407379]

24. Gan WQ, Allen RW, Brauer M, Davies HW, Mancini GB, Lear SA. Long-term exposure to trafficrelated air pollution and progression of carotid artery atherosclerosis: a prospective cohort study. BMJ Open. 2014; 4:e004743.

25. Adar SD, Sheppard L, Vedal S, et al. Fine particulate air pollution and the progression of carotid intima-medial thickness: a prospective cohort study from the Multi-Ethnic Study of Atherosclerosis and Air Pollution. PLoS Med. 2013; 10:e1001430. [PubMed: 23637576]

26. Künzli N, Jerrett M, Garcia-Esteban R, et al. Ambient air pollution and the progression of atherosclerosis in adults. PLoS One. 2010; 5:e9096. [PubMed: 20161713]

27. Stein JH, Korcarz CE, Hurst RT, et al. Use of carotid ultrasound to identify subclinical vascular disease and evaluate cardiovascular disease risk: a consensus statement from the American Society of Echocardiography Carotid Intima-Media Thickness Task Force. Endorsed by the Society for Vascular Medicine. J Am Soc Echocardiogr. 2008; 21:93-111. [PubMed: 18261694]

28. Den Ruijter HM, Peters SA, Anderson TJ, et al. Common carotid intima-media thickness measurements in cardiovascular risk prediction: a meta-analysis. J Am Med Assoc. 2012; 308:796-803.

29. Lorenz MW, Polak JF, Kavousi M, et al. Carotid intima-media thickness progression to predict cardiovascular events in the general population (the PROG-IMT collaborative project): a metaanalysis of individual participant data. Lancet. 2012; 379:2053-62. [PubMed: 22541275]

30. Gepner AD, Young R, Delaney JA, et al. Comparison of coronary artery calcium presence, carotid plaque presence, and carotid intima-media thickness for cardiovascular disease prediction in the Multi-Ethnic Study of Atherosclerosis. Circ Cardiovasc Imaging. 2015; 8:e02262. [PubMed: 25596139] 


\section{Research in context}

Evidence before this study

At study launch, there was no literature on progression of atherosclerosis in relation to long-term exposure to air pollution; the study was in response to the US Environmental Protection Agency's Request For Applications for a prospective observational study of cardiovascular disease initiation and progression associated with long-term exposure to ambient particulate matter and other air pollutants in a population-based sample. Although previous research has been considered to be consistent with a causal relationship between particulate matter air pollution and ischaemic heart disease events and mortality, these studies had substantial limitations and biological plausibility has continued to be questioned. Previous studies have had short follow-up durations, little attention to fine-scale variation in pollutant exposure, and comprised secondary analyses of existing datasets collected to test other hypotheses.

Added value of this study

This study provides important new information about the underlying biological processes of long-term exposure to air pollutant concentrations and their association with cardiovascular disease, through repeated assessment of coronary artery calcification by CT (a surrogate of atherosclerosis extent) in a cohort and with an unprecedented effort to characterise air pollutant exposures. The study was specifically designed to address the hypothesis that air pollutants would be associated with progression in subclinical atherosclerosis.

Exposures assessed in this study are low and relevant for understanding the health effects of ambient environments occurring nowadays in high-income, low-income, and rapidly industrialising countries.

Implications of all the available evidence

Together with accumulating observational evidence of the relationship between ambient pollutants and cardiovascular disease events, this study substantially advances the case for global efforts to reduce exposures to ambient air pollutants. 

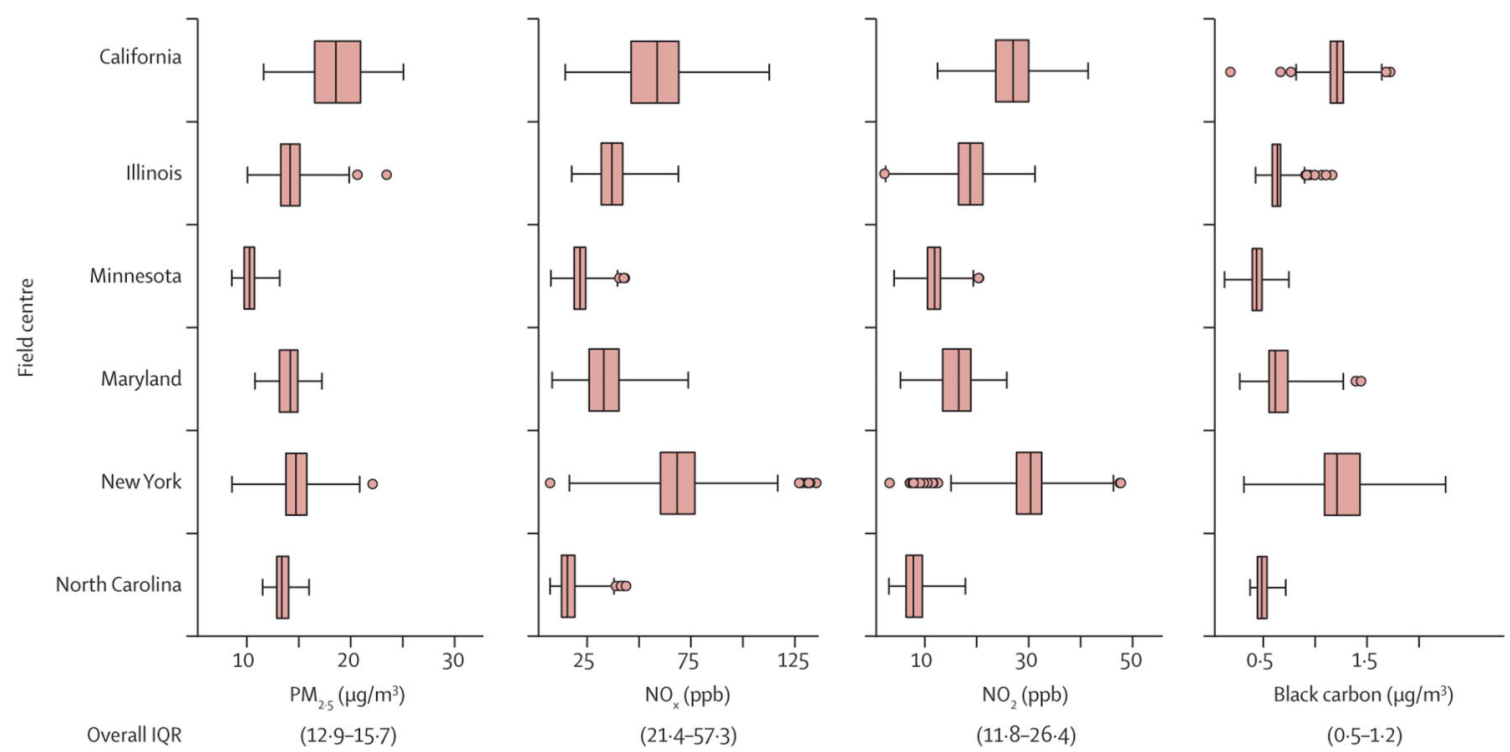

Figure 1. Long-term outdoor air pollutant concentrations by area

Pollutant concentrations are averaged over the time between the first and last CT scan, rounded to the nearest full year. Boxes cover the $25-75^{\text {th }}$ percentile (IQR) with a centre line for the median concentration. Whiskers extend to the highest observation within 3 IQR of the box, with more extreme observations shown as points. Black carbon was measured by light absorption coeff cient, where $0.5 \times 10^{-5} \mathrm{~m}^{-1}$ was approximately equivalent to 0.5 $\mu \mathrm{g} / \mathrm{m}^{3}$ of elemental carbon. $\mathrm{PM}_{2.5}=$ fine particulate matter less than $2.5 \mu \mathrm{m}$ in diameter. $\mathrm{NO}_{\mathrm{X}}=$ nitrogen oxides. $\mathrm{NO}_{2}=$ nitrogen dioxide. $\mathrm{ppb}=$ parts per billion . 
$\mathrm{PM}_{25}$

$\left(\mu \mathrm{g} / \mathrm{m}^{3}\right)$

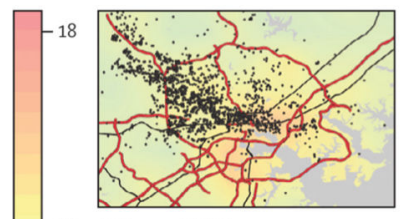

-15 Baltimore, MD PM

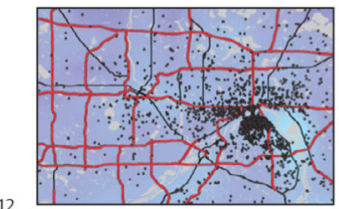

St Paul, MN PM $\mathrm{ppb}=$ parts per billion.
$\mathrm{PM}_{2.5}$

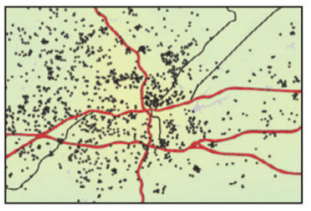

Winston-Salem, NC PM

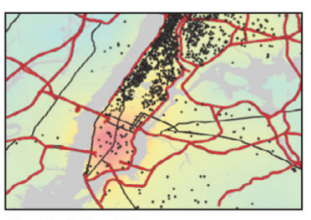

New York City, NY

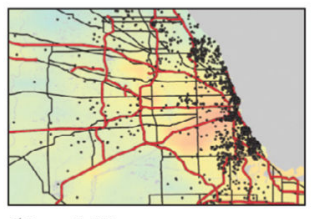

Chicago, IL PM
$\mathrm{No}^{\mathrm{x}}$

$(\mathrm{ppb})$

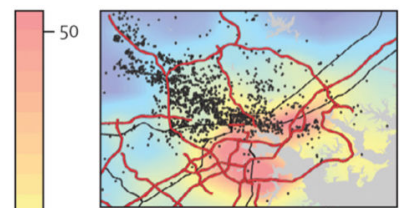

- 37 Baltimore, $\mathrm{MD} \mathrm{NO}_{\mathrm{x}}$
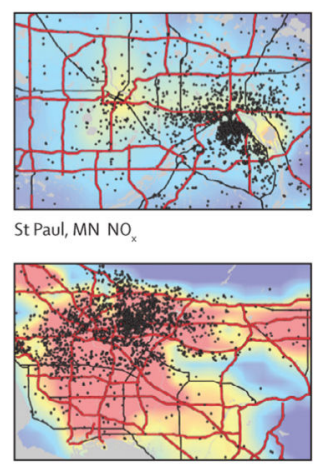

Los Angeles, CA NO
$\mathrm{NO}_{x}$

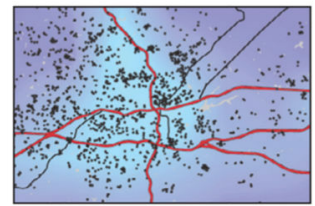

Winston-Salem, $\mathrm{NCNO}_{x}$

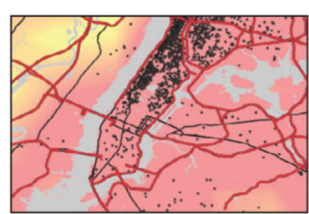

New York City, NY

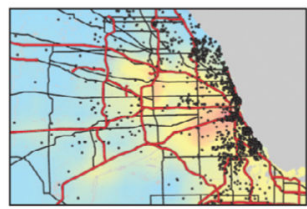

Chicago, IL NO

Figure 2. Maps of predicted $\mathrm{PM}_{2 \cdot 5}$ and $\mathrm{NO}_{X}$ concentrations for 2005 in the MESA Air communities, by the city of the clinical site

Contrasts are smoothed in these figures, which might attenuate the visibility of fine-scale variation. Participant residential locations are shown by black dots, jittered to protect their privacy. $\mathrm{PM}_{2 \cdot 5}=$ fine particulate matter less than $2.5 \mu \mathrm{m}$ in diameter. $\mathrm{NO}_{\mathrm{X}}=$ nitrogen oxides. 
A

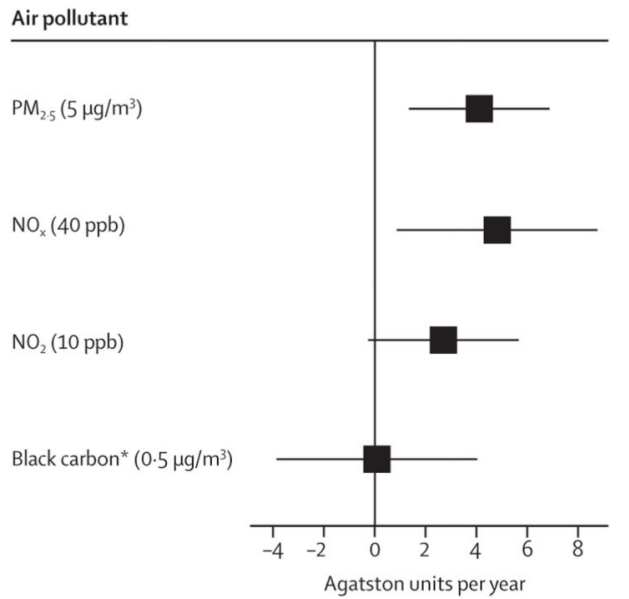

B

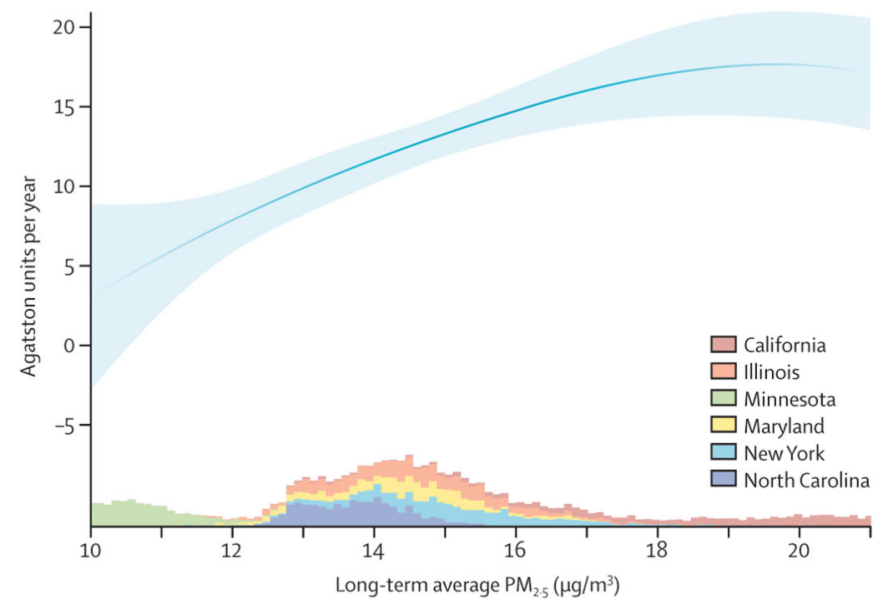

Figure 3. Long-term average air pollutant concentrations and coronary artery calcium progression

(A) The linear longitudinal association of fine particulate matter $\left(\mathrm{PM}_{2.5}\right)$, nitrogen oxides (NOx), nitrogen dioxide $\left(\mathrm{NO}_{2}\right)$, and black carbon, with coronary artery calcium progression (Agatston units per year), from linear mixed models adjusted for age, sex, ethnicity, city, income, employment outside the home, smoking status, second-hand smoke exposure, physical activity, adiposity, cholesterol, statin use, neighbourhood socioeconomic index, income, education and scanner type. (B) The concentration-response curve with $95 \%$ CIs for the overall change in and coronary artery calcium (progression rate associated with longterm average $\mathrm{PM}_{2.5}$ concentrations). The curve is based on a mixed model that includes a thin plate regression spline with five degrees of freedom to more flexibly assess the potentially non-linear association. The relationship at the extremes is less certain and might rely on concentrations that are recorded only in one geographical region; the highest and lowest $5 \%$ of overall concentrations have been trimmed for visualisation. The histogram at the bottom of the right panel shows the relative overall distribution of long-term $\mathrm{PM}_{2.5}$ concentrations in the cohort, with different colours representing each clinic location. *Black carbon as measured by light absorption coefficient, where $0.5 \times 10^{-5} \mathrm{~m}^{-1}$ is approximately equivalent to $0.5 \mu \mathrm{g} / \mathrm{m}^{3}$. 


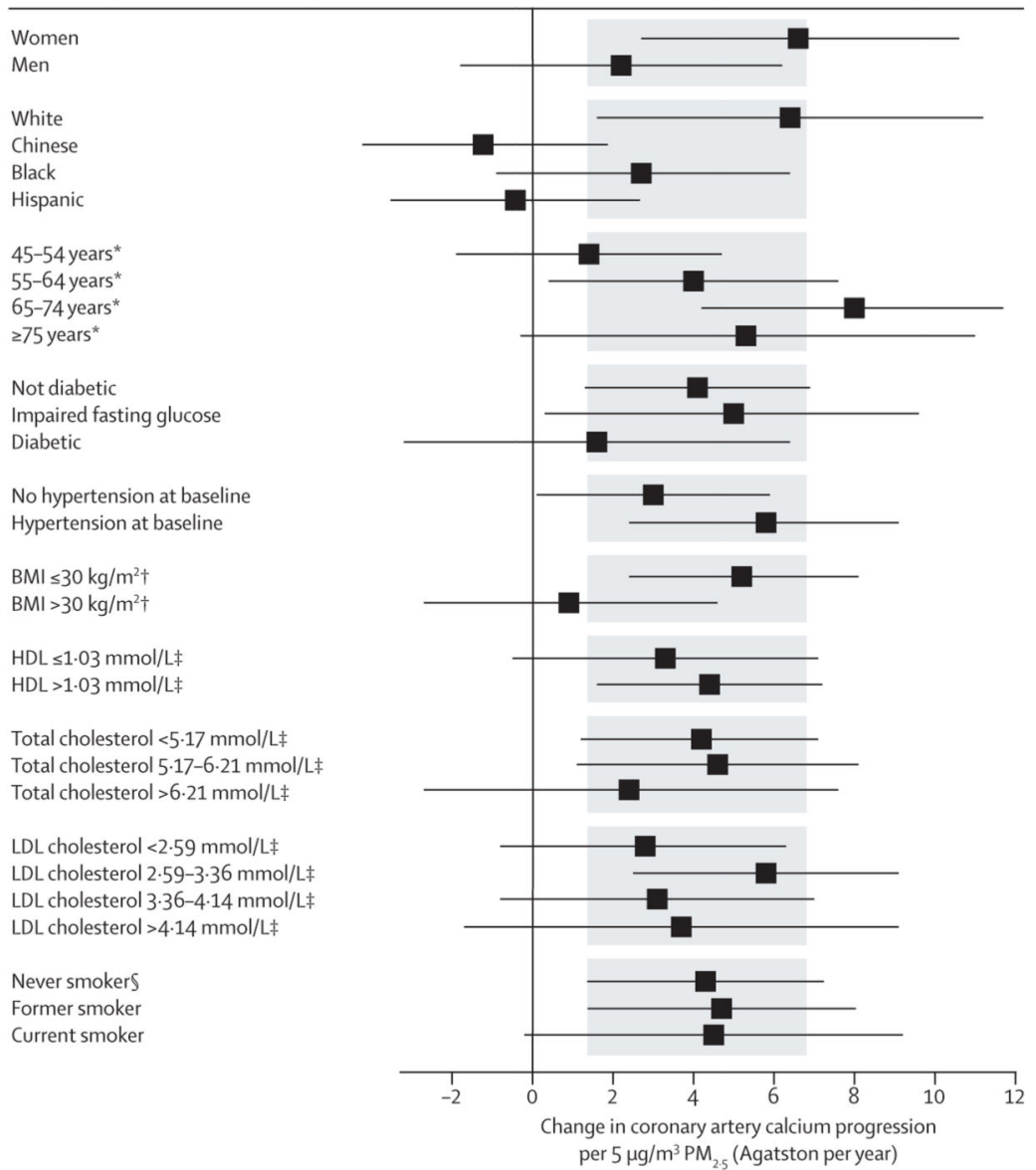

Figure 4. Association between pollutant concentrations and coronary artery calcium progression, by baseline participant characteristics

The shaded region indicates the $95 \%$ confidence interval for the overall association per 5 $\mu \mathrm{g} / \mathrm{m}^{3}$ of $\mathrm{PM}_{2.5}$ * Linear adjustments for age were replaced with categories. $\dagger$ Linear adjustments for adiposity were replaced with indicator for body-mass index $>30 \mathrm{~kg} / \mathrm{m}^{2}$. $\ddagger$ Linear adjustments for cholesterol were replaced with categories. $§ N o t$ adjusted for packyears or second-hand smoke. 


\section{Table}

Participant characteristics at baseline and unadjusted longitudinal outcomes by field centre, for participants included in the analysis of coronary artery calcification

\begin{tabular}{|c|c|c|c|c|c|c|}
\hline & Winston-Salem, NC & $\begin{array}{l}\text { New York } \\
\text { City, NY }\end{array}$ & Baltimore, MD & St Paul, MN & Chicago, IL & $\begin{array}{l}\text { Los Angeles } \\
\text { County, CA }\end{array}$ \\
\hline Year $2000-10 \mathrm{PM}_{2.5}\left(\mu \mathrm{g} / \mathrm{m}^{3}\right)^{*}$ & $13.5(0 \cdot 4)$ & $14.5(1.9)$ & $13 \cdot 7(0 \cdot 8)$ & $10 \cdot 6(0 \cdot 6)$ & $14 \cdot 1(1 \cdot 0)$ & $17 \cdot 7(1 \cdot 3)$ \\
\hline \multicolumn{7}{|l|}{$\mathrm{n}$} \\
\hline Baseline & 1008 & 1166 & 1005 & 1027 & 1143 & 1446 \\
\hline Follow-up & 897 & 1007 & 847 & 898 & 1004 & 1182 \\
\hline Follow-up time (years) & $6 \cdot 4(3 \cdot 5)$ & $6 \cdot 6(3 \cdot 4)$ & $5 \cdot 6(3 \cdot 6)$ & $6 \cdot 5(3 \cdot 4)$ & $6 \cdot 6(3 \cdot 5)$ & $5 \cdot 5(3 \cdot 4)$ \\
\hline \multicolumn{7}{|l|}{ Coronary artery calcium } \\
\hline Baseline (Agatston score) & $143(403)$ & $131(413)$ & $186(462)$ & $172(474)$ & $121(312)$ & $129(374)$ \\
\hline $\begin{array}{l}\text { Progression (Agatston per } \\
\text { year) }\end{array}$ & $26(61)$ & $22(60)$ & $26(63)$ & $26(60)$ & $22(47)$ & $21(52)$ \\
\hline \multicolumn{7}{|l|}{ Demographics } \\
\hline Age (years) & $62(10)$ & $62(10)$ & $63(10)$ & $60(10)$ & $62(10)$ & $63(10)$ \\
\hline Male & $471(47 \%)$ & $521(45 \%)$ & $471(47 \%)$ & $507(49 \%)$ & $537(47 \%)$ & $695(48 \%)$ \\
\hline \multicolumn{7}{|l|}{ Ethnicity } \\
\hline White & $547(54 \%)$ & $281(24 \%)$ & $498(50 \%)$ & $590(57 \%)$ & $542(47 \%)$ & $220(15 \%)$ \\
\hline Chinese & . & $2(0 \%)$ & . & . & $303(27 \%)$ & $490(34 \%)$ \\
\hline Black & $458(45 \%)$ & $395(34 \%)$ & $507(50 \%)$ & . & $298(26 \%)$ & $166(11 \%)$ \\
\hline Hispanic & $3(0 \%)$ & $488(42 \%)$ & . & $437(43 \%)$ & . & $570(39 \%)$ \\
\hline \multicolumn{7}{|l|}{ Education level } \\
\hline Less than high school & $76(8 \%)$ & $271(23 \%)$ & $112(11 \%)$ & $194(19 \%)$ & $84(7 \%)$ & $472(33 \%)$ \\
\hline High school & $211(21 \%)$ & $222(19 \%)$ & $202(20 \%)$ & $224(22 \%)$ & $89(8 \%)$ & $261(18 \%)$ \\
\hline Some college or technical & $314(31 \%)$ & $322(28 \%)$ & $303(30 \%)$ & $359(35 \%)$ & $278(24 \%)$ & $375(26 \%)$ \\
\hline University or graduate & $407(40 \%)$ & $351(30 \%)$ & $388(39 \%)$ & $250(24 \%)$ & $692(61 \%)$ & $338(23 \%)$ \\
\hline \multicolumn{7}{|l|}{ Smoking status } \\
\hline Never & $412(41 \%)$ & $564(48 \%)$ & $432(43 \%)$ & $430(42 \%)$ & $543(48 \%)$ & $872(60 \%)$ \\
\hline Former & $435(43 \%)$ & $429(37 \%)$ & $423(42 \%)$ & $405(39 \%)$ & $451(39 \%)$ & $422(29 \%)$ \\
\hline Present & $161(16 \%)$ & $173(15 \%)$ & $150(15 \%)$ & $192(19 \%)$ & $149(13 \%)$ & $152(11 \%)$ \\
\hline \multicolumn{7}{|l|}{ General health characteristics } \\
\hline Body-mass index $\left(\mathrm{kg} / \mathrm{m}^{2}\right)$ & $29(5)$ & $29(5)$ & $29(6)$ & $29(5)$ & $27(5)$ & $27(5)$ \\
\hline $\begin{array}{l}\text { Systolic blood pressure (mm } \\
\mathrm{Hg})\end{array}$ & $133(22)$ & $124(20)$ & $128(21)$ & $122(20)$ & $124(21)$ & $127(23)$ \\
\hline HDL cholesterol (mmol/L) & $1.32(0 \cdot 39)$ & $1.37(0.39)$ & $1.32(0.39)$ & $1.27(0 \cdot 36)$ & $1.40(0.41)$ & $1.27(0 \cdot 36)$ \\
\hline Total cholesterol $(\mathrm{mmol} / \mathrm{L})$ & $4.89(0.88)$ & $4.99(0.91)$ & $4.97(0.93)$ & $5.17(0.93)$ & $5.04(0.93)$ & $5.07(0.96)$ \\
\hline LDL cholesterol (mmol/L) & $2 \cdot 95(0 \cdot 78)$ & $3.03(0.83)$ & $3 \cdot 03(0 \cdot 80)$ & $3 \cdot 10(0 \cdot 80)$ & $3 \cdot 03(0 \cdot 80)$ & $3 \cdot 05(0 \cdot 85)$ \\
\hline Hypertension & $553(55 \%)$ & $538(46 \%)$ & $515(51 \%)$ & $357(35 \%)$ & $435(38 \%)$ & $626(43 \%)$ \\
\hline Statin use & $164(16 \%)$ & $197(17 \%)$ & $193(19 \%)$ & $126(12 \%)$ & $165(14 \%)$ & $196(14 \%)$ \\
\hline \multicolumn{7}{|l|}{ Diabetes } \\
\hline Normal & $769(76 \%)$ & $831(71 \%)$ & $721(72 \%)$ & $776(76 \%)$ & $908(79 \%)$ & $964(67 \%)$ \\
\hline Impaired fasting glucose & $120(12 \%)$ & $169(14 \%)$ & $155(15 \%)$ & $133(13 \%)$ & $136(12 \%)$ & $242(17 \%)$ \\
\hline
\end{tabular}




\begin{tabular}{lcccccc} 
& Winston-Salem, NC & $\begin{array}{c}\text { New York } \\
\text { City, NY }\end{array}$ & Baltimore, MD & St Paul, MN & Chicago, IL & $\begin{array}{c}\text { Los Angeles } \\
\text { County, CA }\end{array}$ \\
\hline Diabetic & $119(12 \%)$ & $165(14 \%)$ & $126(13 \%)$ & $118(11 \%)$ & $98(9 \%)$ & $240(17 \%)$ \\
\hline
\end{tabular}

Data are mean $(\mathrm{SD})$ or $\mathrm{n}(\%)$. All percentages are calculated using the baseline as the denominator. $\mathrm{PM}_{2} .5=$ fine particulate matter less than $2.5 \mu \mathrm{m}$ in diameter.

$\mathrm{HDL}=$ high density lipoprotein. $\mathrm{LDL}=$ low density lipoprotein

Average of 2-week predictions from January, 2000, to December, 2010, generated at each participant's baseline address.

Based on individually-derived slopes. 